\title{
Estimating the chemical composition of the soil solution of glasshouse soil. 1. Compositions of soil solution and aqueous extracts
}

\section{J. VAN DEN ENDE}

Glasshouse Crops Research Station, P.O. Box 8, NL 2670 AA Naaldwijk, Netherlands

Received 10 May 1989; accepted 29 June 1989

\begin{abstract}
Press extracts, saturation extracts and 1:5 by-weight extracts obtained from 75 glasshouse soils were analysed for electrical conductivity (EC) and $\mathrm{K}, \mathrm{Na}, \mathrm{Ca}, \mathrm{Mg}, \mathrm{NO}_{3}, \mathrm{Cl}, \mathrm{SO}_{4}$, $\mathrm{HCO}_{3}$ and $\mathrm{P}$. The analytical data found are discussed, with the exception of the $\mathrm{HCO}_{3}$ and $\mathrm{P}$ contents of press extracts, as these proved to be much lower than the $\mathrm{HCO}_{3}$ and $\mathrm{P}$ contents of equilibrium solutions of the soils. The water-saturated soil pastes from which the saturation extracts were obtained were prepared from both field-moist and air-dry soil. They stood overnight at $25^{\circ} \mathrm{C}$ before filtration. This overnight storage was unsatisfactory for $\mathrm{NO}_{3}$, as it was found to induce denitrification in the saturated pastes prepared from air-dry soil. Hence, for the determination of $\mathrm{NO}_{3}$ again saturation extracts were prepared from airdry soil, with pastes standing only two hours before filtration. The suspensions from which the 1:5 by-weight extracts were obtained were prepared from air-dry soil and stood overnight at $25{ }^{\circ} \mathrm{C}$ before filtration. Again overnight storage proved unsatisfactory because of denitrification. Thus, for the determination of $\mathrm{NO}_{3}$ again 1:5 suspensions were prepared, this time with a storage period of only two hours.
\end{abstract}

Keywords: soil solution, saturation extract, 1:5 extract, glasshouse soil, electrical conductivity, nutrient elements, denitrification

\section{Introduction}

In routine soil testing, frequent use is made of aqueous soil extracts, particularly for salinity measurements. Such extracts are furthermore employed for determining the level of availability of nutrients, especially in heavily fertilized soils. For an aqueous extract to be useful, its chemical composition should be correlated sufficiently with that of the soil solution. At least, this applies to determinations of salinity and of the level of availability of nutrients in heavily fertilized soils. For the former determinations, the necessity of sufficient correlation is generally accepted (Maas \& Hoffman, 1977), but it also applies to the latter as for the soils in question the chemical composition of the soil solution can generally be seen as the best measure of 
the availability of nutrients, in view of the fact that mass flow of the soil solution accounts for the supply of almost all plant nutrients in sufficient quantities to the crops (van den Ende, 1971).

The correlation mentioned has already been studied for a long time. In early investigations, such as those of Burgess (1922) and Burd \& Martin (1923), comparisons were made between the chemical compositions of extract and soil solution. These investigations were followed by a detailed investigation of Reitemeier (1946), who showed that the relationship in question is influenced by ion exchange, dissolution of solid compounds and negative adsorption.

Subsequent investigations focused on estimating, on an empirical basis, the chemical compositions of soil solutions from those of extracts. However, instead of soil solution, saturation extract was often used. It was assumed that the compositions of soil solution and saturation extract are closely correlated. Such investigations were meant above all to yield estimates of EC values of saturation extracts. Carpena et al. (1968) mentioned several papers in this field. They themselves showed that, in estimating the EC values of saturation extracts from those of 1:5 by-weight extracts, allowance should be made for the sulphate contents and the water-holding capacities of the soils. Drews (1966) found that the water-holding capacity can be derived from the organic-matter content.

Sonneveld \& van den Ende (1971) estimated not only the EC values of saturation extracts but also the contents of a number of nutrients. They based their estimations on both the 1:5 by-weight extract and a specific $1: 2$ by-volume extract. In the former case, the water-holding capacity was estimated from the organic-matter content. Although the estimations were obtained in a simple manner, they proved to be accurate.

Ionic concentrations in soil solutions or saturation extracts can also be estimated in a more sophisticated manner. Using a computer program, Paul et al. (1966) predicted the $\mathrm{Na}, \mathrm{Ca}, \mathrm{Mg}, \mathrm{Cl}$ and $\mathrm{SO}_{4}$ contents of saturation extracts from the contents of 1:1 by-weight extracts. Predicted values corresponded closely with measured values. Recently, Robbins et al. (1980) could successfully predict not only the $\mathrm{Na}, \mathrm{Ca}$ and $\mathrm{Mg}$ contents of soil solutions but also the $\mathrm{K}$ contents. However, for making valid estimations along these lines, various chemical soil characteristics need to be known. It is therefore unlikely that such estimation techniques are usable for routine soil testing.

The investigation described in this paper was carried out to examine the possibilities of estimating the chemical composition of the soil solution of a glasshouse soil from both the composition of a saturation extract and of a 1:5 by-weight extract (henceforth named 1:5 extract). These two extracts were selected because they are frequently used in routine soil testing and because they represent a low and high dilution of soil solution, respectively. Moreover, the selection of the saturation extract opened the possibility to check the assumption that the chemical compositions of soil solutions and saturation extracts are closely correlated.

The investigation was carried out at the Glasshouse Crops Research Station. Its approach was similar to that of Sonneveld \& van den Ende (1971), but in the present investigation the possibilities of estimation were examined more thoroughly. 
In the present paper, the techniques of obtaining soil solutions and extracts, and the ionic concentrations in soil solutions and extracts are discussed.

\section{Materials and methods}

\section{Soils examined}

Soil samples were taken from 75 different glasshouses used for tomato growing. The glasshouses were located in the western part of the Netherlands. The sampling sites were distributed approximately equally over sandy, loamy and peaty soils. Characteristics of the soils were presented in a preceding paper (van den Ende, 1988a). In selecting the sites, care was taken that soils with a wide range in salt and nutrient status were included.

The tomato crops were in their picking stage at sampling time. As a result of frequent watering of soils having adequate internal drainage, the water contents of the soils at sampling time were approximately at field capacity (van den Ende, 1988a).

The samples were taken from the $5-30 \mathrm{~cm}$ layer, excluding the upper $5 \mathrm{~cm}$ layer because of frequent deviations in properties. In the laboratory, the samples were split into two subsamples. One subsample was kept in field-moist condition and the other was dried overnight in a drying cabinet at $50^{\circ} \mathrm{C}$. Subsequently, the dried soil was ground and stored. The soil thus treated will be called air-dry soil.

\section{The techniques of obtaining soil solutions and saturation and 1:5 extracts}

Soil solutions were obtained from field-moist soil samples with the aid of a hydraulic press. For isolation of each of the solutions, use was made of a quantity of soil large enough to contain $400 \mathrm{~cm}^{3}$ of water. From this quantity, $50 \mathrm{~cm}^{3}$ of solution was obtained by pressing.

The isolation of soil solutions was carried out by the Soils Laboratory of the IJsselmeerpolders Development Authority, Lelystad, Netherlands. According to the procedure adopted by this laboratory, the pressure was increased slowly in steps of 1.25 $\mathrm{MPa}$. The final pressure needed to obtain $50 \mathrm{~cm}^{3}$ of solution varied from one soil to another within a range of 2.5-10.0 MPa. Immediately after isolation of the quantity of solution mentioned, it was passed over a filter paper. The solution obtained this way will be called press extract.

It has been shown that most ionic concentrations in press extracts agreed closely with those in equilibrium solutions of the soils. The $\mathrm{P}$ and $\mathrm{HCO}_{3}$ contents of press extracts, however, proved to be generally much lower than those of equilibrium solutions. The low $\mathbf{P}$ contents of press extracts could be ascribed to precipitation of phosphate by iron dissolved from the steel press chamber, and the low $\mathrm{HCO}_{3}$ contents to an acidifying effect of the filter paper used for obtaining the press extracts. The $\mathrm{P}$ and $\mathrm{HCO}_{3}$ contents of press extracts will therefore not be reported.

Saturation extracts were obtained through $50-\mathrm{kPa}$ vacuum filtration of watersaturated soil pastes. These pastes were prepared from both field-móist and air-dry soil samples, according to Richards (1954). After saturation, the samples were 


\section{J. VAN DEN ENDE}

stored overnight at $25^{\circ} \mathrm{C}$. Then, the criteria of saturation were rechecked, and, if necessary, a little water was added to restore the condition of saturation (van den Ende, 1988a). Next, the pastes were subjected to vacuum filtration.

In analysing the saturation extracts, it appeared that the $\mathrm{NO}_{3}$ and $\mathrm{HCO}_{3}$ contents of the extracts 'air-dry' (prepared from air-dry soil) were low and high, respectively, in comparison with those of the extracts 'field-moist' (prepared from fieldmoist soil). It could be shown that microbial denitrification during the overnight saturation period was mainly responsible for the relatively low $\mathrm{NO}_{3}$ contents of the former extracts. The relatively high $\mathrm{HCO}_{3}$ contents of these extracts can also be ascribed to microbial activity.

For a further examination, new saturation extracts were obtained from air-dry soil, in which extracts $\mathrm{NO}_{3}$ and $\mathrm{HCO}_{3}$ were determined. This time, prior to filtration, the soil pastes were stored for only two hours. Hence, no correction of the water contents of the pastes after overnight storage could be made. For this reason, a little extra water was added immediately. Nevertheless, a good agreement was found between the water contents of the pastes stored overnight and for only two hours, the average mass ratios 'water/solid phase' being 0.640 and 0.659 , respectively.

The $\mathrm{NO}_{3}$ and $\mathrm{HCO}_{3}$ contents of saturation extracts 'air-dry' obtained from saturated pastes stored overnight will not be mentioned.

The 1:5 extracts were obtained from air-dry soil. Care was taken to allow for water present in the air-dry soil. The suspensions were shaken for 15 minutes, stored overnight at $25{ }^{\circ} \mathrm{C}$, shaken again for 15 minutes and finally passed over a filter paper.

For a repeated determination of $\mathrm{NO}_{3}$ and $\mathrm{HCO}_{3}$, because of microbial activities as mentioned above, new 1:5 extracts were obtained in a shortened procedure. This time, prior to filtration, the suspensions were stored for only two hours. The $\mathrm{NO}_{3}$ and $\mathrm{HCO}_{3}$ contents of $1: 5$ extracts obtained from suspensions stored overnight will not be reported.

\section{Chemical analyses performed}

The press, saturation and 1:5 extracts were analysed for $\mathrm{EC}, \mathrm{K}, \mathrm{Na}, \mathrm{Ca}, \mathrm{Mg}, \mathrm{NO}_{3}$, $\mathrm{Cl}, \mathrm{SO}_{4}, \mathrm{HCO}_{3}$ and $\mathrm{P}$. In the following, the methods will be described briefly:

- EC was measured at $25^{\circ} \mathrm{C}$. This temperature was obtained with the aid of a water bath, in which fluctuations were $\pm 0.1{ }^{\circ} \mathrm{C}$.

- Determinations of $\mathrm{K}$ and $\mathrm{Na}$ were carried out flame-photometrically.

- $\mathrm{Ca}$ and $\mathrm{Mg}$ were determined titrimetrically with EDTA, according to Bower \& Wilcox (1965).

- For determining $\mathrm{NO}_{3}$, use was made of the phenoldisulfonic acid method, as modified (unpublished) in the Drinking Water Laboratory of the Municipality of Rotterdam, Netherlands.

- $\mathrm{Cl}$ was determined titrimetrically with mercury (II) nitrate.

- $\mathrm{SO}_{4}$ determinations were carried out gravimetrically.

- $\mathrm{HCO}_{3}$ contents were estimated from alkalinity determinations. These were con- 
ducted by titrating aliquots of diluted extract to $\mathrm{pH}$ 5.3.

None of the extracts had a $\mathrm{pH}$ higher than 8.1. This implies that no $\mathrm{CO}_{3}$ and $\mathrm{OH}$ ions were present in titratable quantities. No corrections were made for other compounds that were titrated along with $\mathrm{HCO}_{3}$.

- $\mathrm{P}$ was determined according to the molybdenum blue method with metol and tin (II) chloride used as reducing agents.

Single analyses were carried out on duplicate extracts. When the pairs of values thus obtained showed a high degree of variability, the analyses were repeated on the same extracts. From the duplicate values, the coefficients of variation were calculated. These were generally found to be lower than $5 \%$, with the exception of the hydrogen carbonate determinations on saturation and 1:5 extracts, which averaged at approximately $10 \%$.

\section{Results and discussion}

A summary of the results of the analyses performed on the extracts is given in Tables 1 and 2. The results reported for $\mathrm{NO}_{3}$ and $\mathrm{HCO}_{3}$ in 1:5 extracts and in saturation extracts 'air-dry' are those found for procedures in which 1:5 suspensions and saturated pastes were stored for two hours.

On eight soil samples, it was examined whether the difference in length of storage period (two hours versus overnight) for the 1:5 suspensions and saturated pasts 'airdry' influenced the results of the determinations other than those of $\mathrm{NO}_{3}$ and $\mathrm{HCO}_{3}$. Such influences were usually absent, but for the two-hour storage the mean $P$ contents of both 1:5 extracts and saturation extracts 'air-dry' were $6 \%$ lower than for the overnight period. Further, the mean Ca contents of the 1:5 extracts were $5 \%$ lower for the two-hour period. These differences among $\mathrm{P}$ and $\mathrm{Ca}$ contents were considered too small to necessitate the use of a two-hour storage period for analysing $\mathrm{P}$ and $\mathrm{Ca}$ in 1:5 and saturation extracts of all air-dry soil samples.

It can be seen from the data mentioned in Tables 1 and 2 that, with the exception of $\mathrm{P}$, all ionic species contributed markedly to the total salt concentrations of the extracts. The only remaining ionic species which could make sizeable contributions to the total salt concentration are $\mathrm{NH}_{4}$ and $\mathrm{NO}_{2}$. However, as a rule, the quantities of these species in water-soluble form in glasshouse soils are small. In mildly acid, neutral and alkaline glasshouse soils, considerable quantities of water-soluble $\mathrm{NH}_{4}$ and $\mathrm{NO}_{2}$ can be expected to occur only for periods up to two months after a partial-sterilization treatment by means of steam or chemicals, or for a few weeks after the application of a basal dressing of ammonium compounds or organic substances (Elliot et al., 1977; Mastalerz, 1977; Sonneveld, 1979; Vilsmeier \& Amberger, 1980). Since no soils included in the present investigation were too acid for growing vegetable crops and the soils were collected several months after a possible sterilization treatment or basal fertilizer or manure application, it is considered unlikely that $\mathrm{NH}_{4}$ or $\mathrm{NO}_{2}$ made any sizeable contribution to the total salt concentrations of the extracts. The possible presence of $\mathrm{NH}_{4}$, of these two species being the more prominent one in soil solutions, was examined. None of the extracts appeared to contain a quantity of $\mathrm{NH}_{4}$ worth being considered. 


\section{J. VAN DEN ENDE}

Table 1. Means and range values of determinations performed on press extracts and saturation extracts obtained from field-moist and air-dry soil samples.

\begin{tabular}{|c|c|c|c|c|c|c|}
\hline \multirow[t]{3}{*}{ Determination 1} & \multicolumn{2}{|c|}{ Press extracts } & \multicolumn{4}{|c|}{ Saturation extracts } \\
\hline & \multirow[t]{2}{*}{ mean } & \multirow[t]{2}{*}{ range } & \multicolumn{2}{|c|}{$\begin{array}{l}\text { from field-moist } \\
\text { soil samples }\end{array}$} & \multicolumn{2}{|c|}{$\begin{array}{l}\text { from air-dry } \\
\text { soil samples }\end{array}$} \\
\hline & & & mean & range & mean & range \\
\hline $\mathrm{EC}$ & 6.70 & $3.35-10.82$ & 4.39 & $2.24-6.70$ & 4.55 & $2.32-6.59$ \\
\hline $\mathrm{K}$ & 6.4 & $2.1-17.4$ & 4.9 & $0.9-13.3$ & 4.3 & $1.1-13.6$ \\
\hline $\mathrm{Na}$ & 13.6 & $5.8-26.3$ & 8.9 & $3.4-20.1$ & 9.6 & $3.7-21.5$ \\
\hline $\mathrm{Ca}$ & 24.9 & $10.9-36.2$ & 15.1 & $5.8-22.6$ & 16.7 & $6.8-22.4$ \\
\hline $\mathrm{Mg}$ & 9.4 & $4.0-19.4$ & 5.3 & $1.7-11.2$ & 5.5 & $1.7-11.0$ \\
\hline $\mathrm{NO}_{3}$ & 20.7 & $2.9-44.8$ & 12.1 & $1.4-27.1$ & 14.1 & $2.6-28.9$ \\
\hline $\mathrm{Cl}$ & 16.2 & $5.9-37.1$ & 8.2 & $3.0-20.5$ & 9.7 & $3.6-24.4$ \\
\hline $\mathrm{SO}_{4}$ & 22.8 & $10.0-32.8$ & 15.1 & $4.9-21.8$ & 16.7 & $4.9-22.6$ \\
\hline $\mathrm{HCO}_{3}$ & . & . & 1.0 & $0.2-2.5$ & 1.0 & $0.2-2.5$ \\
\hline $\mathrm{P}$ & . & . & 0.21 & $0.03-0.75$ & 0.16 & $0.02-0.48$ \\
\hline
\end{tabular}

$1 \mathrm{EC}$ in $\mathrm{dS} \mathrm{m}^{-1}$ at $25^{\circ} \mathrm{C}$ and ionic species in $\mathrm{mol} \mathrm{m}^{-3}$.

Table 2. Means and range values of determinations performed on 1:5 extracts of soils of five soil type classes.

\begin{tabular}{|c|c|c|c|c|c|c|c|}
\hline \multirow[t]{3}{*}{ Determination $^{1}$} & \multicolumn{6}{|c|}{ Mean } & \multirow{3}{*}{$\begin{array}{l}\text { Range } \\
\text { all } \\
\text { soils }\end{array}$} \\
\hline & \multirow{2}{*}{$\begin{array}{l}\text { all } \\
\text { soils }\end{array}$} & \multicolumn{5}{|c|}{ soil type class ${ }^{2}$} & \\
\hline & & 1 & 2 & 3 & 4 & 5 & \\
\hline $\mathrm{EC}$ & 0.93 & 0.66 & 0.59 & 0.84 & 1.07 & 1.44 & $0.40-1.77$ \\
\hline $\mathbf{K}$ & 1.1 & 0.9 & 0.9 & 0.8 & 1.1 & 1.8 & $0.2-2.5$ \\
\hline $\mathrm{Na}$ & 1.7 & 0.9 & 0.8 & 1.4 & 2.2 & 2.8 & $\begin{array}{lll}0.3 & -4.7\end{array}$ \\
\hline $\mathrm{Ca}$ & 2.6 & 1.6 & 1.6 & 2.6 & 3.1 & 4.0 & $0.8 \quad-5.6$ \\
\hline $\mathrm{Mg}$ & 0.8 & 0.7 & 0.5 & 0.7 & 1.0 & 1.3 & $0.2-1.9$ \\
\hline $\mathrm{NO}_{3}$ & 1.7 & 1.5 & 1.0 & 1.3 & 1.5 & 3.2 & $0.2-5.5$ \\
\hline $\mathrm{Cl}$ & 1.2 & 0.8 & 0.6 & 0.9 & 1.6 & 2.0 & $\begin{array}{lll}0.2 & -3.5\end{array}$ \\
\hline $\mathrm{SO}_{4}$ & 2.7 & 1.7 & 1.5 & 2.6 & 3.4 & 4.2 & $0.6-6.5$ \\
\hline $\mathrm{HCO}_{3}$ & 0.5 & 0.3 & 0.5 & 0.6 & 0.5 & 0.4 & $0.1-1.2$ \\
\hline $\mathrm{P}$ & 0.16 & 0.18 & 0.16 & 0.14 & 0.13 & 0.19 & $0.03-0.53$ \\
\hline
\end{tabular}

${ }^{1} \mathrm{EC}$ in $\mathrm{dS} \mathrm{m}-1$ at $25^{\circ} \mathrm{C}$ and ionic species in $\mathrm{mol} \mathrm{m}^{-3}$.

2 Based on the mass fraction organic matter of oven-dry soil $\left(f_{\mathrm{H}}\right)$, the soils were grouped as follows: $f_{\mathrm{H}}<0.1$ (soil type classes 1,2 and 3 ), $f_{\mathrm{H}}$ between 0.1 and 0.2 (class 4 ) and $f_{\mathrm{H}}>0.2$ (class 5). The first category was subdivided according to the mass fraction clay of oven-dry soil $\left(f_{\mathrm{C}}\right)$. as follows: $f_{\mathrm{C}}<0.05$ (class 1 ), $f_{\mathrm{C}}$ between 0.05 and 0.15 (class 2) and $f_{\mathrm{C}}>0.15$ (class 3 ). 
As can be seen from the Tables 1 and 2, particularly $\mathrm{Ca}, \mathrm{SO}_{4}$ and $\mathrm{NO}_{3}$ were found to be present in large quantities. In the saturation extracts 'field-moist', these species constituted 21,21 and $17 \%$ of total ions, respectively. $\mathrm{Na}$ and $\mathrm{Cl}$, which were present in considerable quantities as well, together accounted for $25 \%$ of total ions. For both $\mathrm{Mg}$ and $\mathrm{K}$, the percentage amounted to 7 . Finally, for $\mathrm{HCO}_{3}$ and $\mathrm{P}$ the percentages were 1.4 and 0.3 , respectively.

Table 1 shows that the ionic concentrations in the saturation extracts 'field-moist' were as a rule somewhat lower than those in the saturation extracts 'air-dry'. This observation is consonant with the finding that the water contents of the saturated pastes 'field-moist' were higher than those of the saturated pastes 'air-dry' (van den Ende, 1988a). However, $K$ and $P$ behaved aberrantly in that the quantities of these ionic species were generally lower in the extracts 'air-dry'.

The aberrant behaviour of $\mathrm{K}$ can undoubtedly be accounted for as resulting directly from soil drying that was put into practice for the preparation of saturation extracts 'air-dry'. The solubility of soil potassium was depressed by this drying, and this depression must be attributed to potassium fixation. This phenomenon is generally believed to be due mainly to contraction of the lattices of expanded 2:1-type clay minerals (Goulding, 1983). The phenomenon has also been reported to occur in moist soils. However, it is usually aggravated by soil drying. If a soil is dried after addition of a considerable amount of potassium, the phenomenon very often manifests itself (Schuffelen \& van der Marel, 1955).

A further comparison of the $\mathrm{K}$ contents of both types of saturation extract shows that in our investigation particularly the soils of soil type classes 2 and 3 (see note 2 in Table 2) fixed a fair amount of potassium. As could be expected on the basis of their low clay contents, the soils of soil type class 1 fixed but little potassium.

The lowering of the $P$ values by air-drying is in agreement with results presented by Wiklander \& Koutler-Andersson (1966) and Ghosh \& Wiklander (1968) who reported that air-drying of soils in many cases resulted in a reduction of the solubility of phosphate. Wiklander \& Koutler-Andersson (1966) supplied several explanations for such a reduction. They drew attention to the fact that a dehydration of colloidal materials, such as iron, aluminium and calcium phosphates in soil, may lead to a lowering of the solubility of these matererials. Furthermore, they pointed out that oxidation of iron (II) to iron (III) compounds, which may occur on drying, is likely to induce the formation of insoluble iron (III) phosphates, and that drying of soils may result in precipitation and/or sorption of phosphate in forms solubilized and desorbed only slowly upon remoistening.

The explanation of the lower $\mathbf{P}$ concentration in saturation extracts 'air-dry' than in saturation extracts 'field-moist' must perhaps be sought not only in physical and chemical factors but also in a microbial factor. Both denitrification and a high level of hydrogen carbonate production (see below) in saturated pastes 'air-dry' stored overnight indicate that in these pastes microbial activities started soon after saturation was induced. Therefore, it is not unlikely that for the build-up of their tissue micro-organisms utilized inorganic phosphate withdrawn from the aqueous phase of said pastes. Such a withdrawal might account for a lower $P$ concentration in the saturation extracts 'air-dry' in comparison with the saturation extracts 'field-moist'. 
This reasoning is supported by data of White (1964). He observed that on shaking soil suspensions for some hours the amount of inorganic phosphate in solution was reduced due to uptake of phosphate by micro-organisms, the reduction commencing earlier and being more marked for air-dried than for field-moist soils. Also other workers (Birch, 1964; Gupta \& Rorison, 1974) found that the flush of microbial activity following the wetting of a dry soil may lead to a considerable phosphate immobilization.

It has to be remarked that a number of workers (Beckett \& White, 1964; Bartlett \& James, 1980; Sparling et al., 1985) reported that drying of soils resulted in increased solubility of phosphate. Such an increase was not observed to any extent in our investigation. Only with 4 out of the 75 soils employed, the amount of phosphate extracted by the saturation extraction procedure 'air-dry' was higher than that extracted by the procedure 'field-moist', and in these 4 cases the differences were only small.

It is not likely that the $\mathrm{NO}_{3}$ values of extracts obtained from 1:5 suspensions or saturated pastes 'air-dry' that stood two hours before filtration, were affected by denitrification, because this storage period is too short for inducing this process (Bremner \& Shaw, 1958; Smith \& Tiedje, 1979; Leffelaar \& Wessel, 1988). The average $\mathrm{NO}_{3}$ value of saturation extracts 'air-dry' (two hours) of all soils employed turned out to be $14.1 \mathrm{~mol} \mathrm{~m}^{-3}$ (Table 1). Adjustment of this value from the water contents of saturated pastes 'air-dry' (two hours) to the water contents of saturated pastes 'field-moist' yields the value $12.4 \mathrm{~mol} \mathrm{~m}^{-3}$. This value agrees well with the value $12.1 \mathrm{~mol} \mathrm{~m}^{-3}$ found for the saturation extracts 'field-moist'. This observation suggests that at the end of the overnight saturation of field-moist soil samples, denitrification had not yet started. Obviously, this reasoning is only valid, if the $\mathrm{NO}_{3}$ contents of the soil samples were not reduced by drying the samples. Experience gained in analysing glasshouse soils in our soils laboratory justifies the statement that such a reduction will not have occurred.

Denitrification occurring in saturated pastes 'air-dry' (overnight) proved that drying of soil samples prior to water-saturating was conducive to denitrification. In this connection, it should be remarked that a drying process enhances the ease with which organic matter can be attacked by micro-organisms (Skyring \& Thompson, 1966; McKenzie \& Kurtz, 1976; Patten et al., 1980), and that in soil the reducing power during denitrification is mainly supplied by organic compounds (Burford \& Bremner, 1975; Stanford et al., 1975; Reddy et al., 1982). In addition, these organic compounds stimulate the activity of microbes responsible for anaerobic conditions.

The onset of denitrification in a soil after waterlogging is often preceded by a lag period. It may be assumed that the length of such a lag period is determined by the time needed to exhaust the free oxygen initially present and by the lag phase that may occur in the nitrate-reducing activities of the denitrifiers (Greenwood, 1962; Smith \& Tiedje, 1979; Knowles, 1982). The data presented above suggest that for the saturated pastes 'field-moist' and 'air-dry' (overnight) the lag period referred to was longer and shorter, respectively, than the overnight saturation period.

Besides denitrification, also microbial assimilation of nitrate may have contributed to the reduction of the $\mathrm{NO}_{3}$ contents of saturated pastes 'air-dry' (overnight). 
However, investigations of several workers (Knowles, 1982; Reddy et al., 1982; Patrick, 1982) show that during denitrification nitrate loss due to microbial assimilation is comparatively small or even practically absent.

The aforesaid data also suggest that during the overnight storage of saturated pastes 'field-moist' decomposition of soil organic matter was virtually absent. Since decomposition of soil organic matter results in production of $\mathrm{CO}_{2}$ and since, at the $\mathrm{pH}$ values prevailing in the soils under examination, the $\mathrm{CO}_{2}$ produced will be partially converted to $\mathrm{HCO}_{3}$, any occurrence of higher $\mathrm{HCO}_{3}$ contents in saturation extracts 'air-dry' (overnight) in comparison with saturation extracts 'field-moist' could be accounted for by postulating a decomposition of organic matter in saturated pastes 'air-dry' (overnight) and a delay of such a decomposition in saturated pastes 'field-moist'. However, the $\mathrm{HCO}_{3}$ contents of saturation extracts 'fieldmoist' were generally not lower than those of saturation extracts 'air-dry' (two hours) (Table 1).

In water extractions based on a fixed soil/water weight ratio, it is normally observed that ionic concentrations in the extract are increasing with increasing waterholding capacities of the soils examined (Drews, 1966; Sonneveld \& van den Ende, 1971). This correlation finds its origin in the fact that the quantities of soluble ions most often depend in the first place on the amount of water held by the soils at field capacity. Since the soils in the various soil type classes employed in our investigation displayed a rather wide variation in water-holding capacity (van den Ende, 1988a, b) and, hence, also in ionic concentrations in the 1:5 extracts, the results of the determinations performed on these extracts are presented in Table 2 both for the various soil type classes individually and averaged over all soils. It is evident from the data that in general the results are in agreement with the above-mentioned observation. Deviations from this rule will mainly have been caused by random variations in the chemical composition of sampled glasshouse soils.

Only for $\mathrm{HCO}_{3}$ and $\mathrm{P}$, the correlations between concentration and waterholding capacity were absent, since for both of these constituents the values remained relatively constant throughout the soil type class range from low to high water-holding capacity. This anomalous behaviour is likely to be explained by referring to the relative insolubilities of phosphates and carbonates (Sissingh, 1969; Marion \& Babcock, 1977). In other words, the quantities of $\mathrm{HCO}_{3}$ and $\mathrm{P}$ that went into solution were directly dependent not so much on the water-holding capacities of the soils but rather on the quantity of water added to the soils, assuming that relatively large quantities of phosphate and carbonate salts were present in solid form. For both salts, this assumption is justified, since in the first place all soils contained measurable quantities of solid carbonate, and in the second place past fertilizer practices have no doubt resulted in substantial precipitation of phosphates in these soils.

It may be assumed that the differences in $\mathrm{HCO}_{3}$ levels between the 1:5 extracts 'overnight' and 'two hours' were for a small part due to dissolution of calcium carbonate. This assumption arises from data, reported above, concerning Ca contents found in 1:5 extracts 'overnight' and 'two hours'. 


\section{J. VAN DEN ENDE}

\section{Conclusions}

In press extracts of glasshouse soils from the western part of the Netherlands, $\mathrm{NO}_{3}, \mathrm{Ca}$ and $\mathrm{SO}_{4}$ turned out to be the more abundant ionic species. Together, these species constituted about $60 \%$ of total ions. $\mathrm{Cl}$ and $\mathrm{Na}$, which were present in considerable quantities as well, together comprised about $25 \%$. For $\mathrm{K}$ and $\mathrm{Mg}$, the percentages lay between 5 and 10. Finally, for $\mathrm{HCO}_{3}$ and $\mathrm{P}$ the percentages were low and very low, respectively.

Consonant with the earlier finding that the water contents of water-saturated pastes 'field-moist' (prepared from field-moist soils) were higher than those of water-saturated pastes 'air-dry' (prepared form air-dry soils), the values representing the chemical compositions of saturation extracts 'field-moist' were as a rule somewhat lower than those representing the chemical compositions of saturation extracts 'air-dry'. However, $\mathrm{K}$ and $\mathrm{P}$ behaved aberrantly in that the quantities of these ionic species were generally lower in the extracts 'air-dry'. The aberrant behaviour of $\mathrm{K}$ must be attributed to potassium fixation, and that of $\mathrm{P}$ must perhaps be sought in both physical and chemical factors and a microbial factor.

Values of electrical conductivity and of $\mathrm{K}, \mathrm{Na}, \mathrm{Ca}, \mathrm{Mg}, \mathrm{NO}_{3}, \mathrm{Cl}$ and $\mathrm{SO}_{4}$ in 1:5 extracts generally increased with increasing water-holding capacity of the soil. For $\mathrm{P}$ and $\mathrm{HCO}_{3}$, such a correlation with the water-holding capacity did not occur, due to the relative insolubility of phosphates and carbonates in the soil and the presence of relatively large quantities of such salts in solid form.

Overnight storage of 1:5 suspensions and saturated pastes 'air-dry' proved to be unsatisfactory for $\mathrm{NO}_{3}$, as it induced denitrification. Storing such suspensions and pastes for only two hours yielded correct $\mathrm{NO}_{3}$ values.

Further conclusions and a general discussion will be presented in the second paper of this series (van den Ende, 1989).

\section{References}

Bartlett, R. \& B. James, 1980. Studying dried, stored soil samples. Some pitfalls. Soil Science Society of America Journal 44: 721-724.

Beckett, P. H. T.\& R. E. White, 1964. Studies on the phosphate potentials of soils. 3 . The pool of labile inorganic phosphate. Plant and Soil 21: 253-282.

Birch, H. F., 1964. The effect of 2:4-dinitro-phenol on phosphorus transformations during humus decomposition. Plant and Soil 21: 391-394.

Bower, C. A. \& L. V. Wilcox, 1965. Soluble salts. In: C. A. Black (Ed.), Methods of Soil Analysis, p. 933-951. American Society of Agronomy, Madison, Wisconsin.

Bremner, J. M. \& K. Shaw, 1958. Denitrification in soil. 1. Methods of investigation. Journal of Agricultural Science (Cambridge) 51: 22-39.

Burd, J. S. \& J. C. Martin, 1923. Water displacement of soils and the soil solution. The Journal of Agricultural Science 13: 265-295.

Burford, J. R. \& J. M. Bremner, 1975. Relationships between the denitrification capacities of soils and total, water-soluble and readily decomposable soil organic matter. Soil Biology and Biochemistry 7: 389-394. 
Burgess, P. S., 1922. The soil solution, extracted by Lipman's direct-pressure method, compared with 1:5 water extracts. Soil Science 14: 191-212.

Carpena, O., M. G. Guillén, F. G. Fernández \& M. Caro, 1968. Saline soil classification using the 5:1 aqueous extract. Transactions 9th International Congress of Soil Science (Adelaide), Vol. 1, p. 483-490.

Drews, M., 1966. Ermittlung der Salzschadgrenze für einige unter Glas angebaute Gemüsearten. Archiv für Gartenbau 14: 553 his 68 .

Elliot, J. M., C. F. Marks \& C. M. Tu, 1977. Effects of certain nematicides on soil nitrogen, soil nitrifiers, and populations of Pratylenchus penetrans in flue-cured tobacco. Canadian Journal of Plant Science 57: 143-154.

Ende, J. van den, 1971. Extraction methods for the determination of major elements in greenhouse soils and potting- and culture media. Acta Horticulturae 29: 125-139.

Ende, J. van den, 1988a. Water contents of glasshouse soils at field capacity and at saturation. 1. Relationships between water contents. Netherlands Journal of Agricultural Science 36: 265-274.

Ende, J. van den, 1988b. Water contents of glasshouse soils at field capacity and at saturation. 2. Estimating water contents from organic-matter and clay contents or from loss-on-ignition. Netherlands Journal of Agricultural Science 36: 275-282.

Ende, J. van den, 1989. Estimating the chemical composition of the soil solution of glasshouse soil. 2 . Relationships between the compositions of soil solution and aqueous extracts. Netherlands Journal of Agricultural Science 37: 323-334.

Ghosh, S. K. \& L. Wiklander, 1968. Solubility of soil phosphate as influenced by drying. Lantbrukshögskolans Annaler 34: 337-349.

Goulding, K. W. T., 1983. Thermodynamics and potassium exchange in soils and clay minerals. $A d-$ vances in Agronomy 36: 215-264.

Greenwood, D. J., 1962. Nitrification and nitrate dissimilation in soil. 1. Method of studying nitrate dissimilation. Plant and Soil 17: 365-377.

Gupta, P. L.\& I. H. Rorison, 1974. Effects of storage on the soluble phosphorus and potassium content of some Derbyshire soils. Journal of Applied Ecology 11: 1185-1192.

Knowles, R., 1982. Denitrification. Microbiological Reviews 46: 43-70.

Leffelaar, P. A. \& W. W. Wessel, 1988. Denitrification in a homogeneous, closed system: Experiment and simulation. Soil Science 146: 335-349.

Maas, E. V. \& G. J. Hoffman, 1977. Crop salt tolerance - Current assessment. Journal of the Irrigation and Drainage Division, American Society of Civil Engineers 103 (IR2): 115-134.

Marion, G. M. \& K. L. Babcock, 1977. The solubilities of carbonates and phosphates in calcareous soil suspensions. Soil Science Society of America Journal 41: 724-728.

Mastalerz, J. W., 1977. The greenhouse environment. John Wiley \& Sons, New York, 629 pp.

McKenzie, E. \& L. T. Kurtz, 1976. Effect of pretreatment on loss of nitrogen-15-labelled fertilizer nitrogen from waterlogged soil during incubation. Soil Science Society of America Journal 40: 534-537.

Patrick, W. H., 1982. Nitrogen transformations in submerged soils. In: F. J. Stevenson (Ed.), Nitrogen in agricultural soils, p. 449-465. American Society of Agronomy, Madison, Wisconsin.

Patten, D. K., J. M. Bremner \& A. M. Blackmer, 1980. Effects of drying and air-dry storage of soils on their capacity for denitrification of nitrate. Soil Science Society of America Journal 44: 67-70.

Paul, J. L., K. K. Tanji \& W. D. Anderson, 1966. Estimating soil and saturation extract composition by a computer method. Soil Science Society of America Proceedings 30: 15-17.

Reddy, K. R., P. S. C. Rao \& R. E. Jessup, 1982. The effect of carbon mineralization on denitrification kinetics in mineral and organic soils. Soil Science Society of America Journal 46: 62-68.

Reitemeier, R. F., 1946. Effect of moisture content on the dissolved and exchangeable ions of soils of arid regions. Soil Science 61: 195-214.

Richards, L. A. (Ed.), 1954. Diagnosis and improvement of saline and alkali soils. Agriculture Handbook No 60. United States Department of Agriculture, US Government Printing Office, Washington, DC, $160 \mathrm{pp}$.

Robbins, C. W., J. J. Jurinak \& R. J. Wagenet, 1980. Calculating cation exchange in a salt transport model. Soil Science Society of America Journal 44: 1195-1200.

Schuffelen, A. C. \& H. W. van der Marel, 1955. Potassium fixation in soils. In: Potassium-Symposium 1955, p. 157-201. International Potash Institute, Berne.

Netherlands Journal of Agricultural Science 37 (1989) 


\section{J. VAN DEN ENDE}

Sissingh, H. A., 1969. Die Lösung der Bodenphosphorsäure bei wäszriger Extraktion in Verbindung mit der Entwicklung einer neuen P-Wasser-Methode. Landwirtschaftliche Forschung, Sonderheft 23/2: $110-120$.

Skyring, G. W. \& J. P. Thompson, 1966. The availability of organic matter in dried and undried soil, estimated by an anaerobic respiration technique. Plant and Soil 24: 289-298.

Smith, M. S. \& J. M. Tiedje, 1979. Phases of denitrification following oxygen depletion in soil. Soil Biology and Biochemistry 11: 261-267.

Sonneveld, C., 1979. Changes in chemical properties of soil caused by steam sterilization. In: D. Mulder (Ed.), Soil Disinfestation, p. 39-50. Elsevier, Amsterdam.

Sonneveld, C. \& J. van den Ende, 1971. Soil analysis by means of a 1:2 volume extract. Plant and Soil 35: 505-516.

Sparling, G. P., K. N. Whale \& A. J. Ramsay, 1985. Quantifying the contribution from the soil microbial biomass to the extractable P levels of fresh and air-dried soils. Australian Journal of Soil Research 23: 613-621.

Stanford, G., R. A. van der Pol \& S. Dzienia, 1975. Denitrification rates in relation to total and extractable soil carbon. Soil Science Society of America Proceedings 39: 284-289.

Vilsmeier, K. \& A. Amberger, 1980. Umsetzung von Cyanamid, Harnstoff und Ammonsulfat in Abhängigkeit von Temperatur und Bodenfeuchtigkeit. Zeitschrift für Pflanzenernährung und Bodenkunde 143: 47-54.

White, R. E., 1964. Studies on the phosphate potentials of soils. 2. Microbial effects. Plant and Soil 20: 184-193.

Wiklander, L. \& E. Koutler-Andersson, 1966. Effect of air-drying on the solubility of soil phosphate. Lantbrukshögskolans Annaler 32: 309-317. 